\title{
LINKING GUN AVAILABILITY TO YOUTH GUN VIOLENCE
}

\author{
Alfred Blumstein* AND DANiEl CORK ${ }^{* *}$
}

\section{I \\ INTRODUCTION: \\ HOMICIDE RATES IN THE UNITED STATES}

In the United States, opinion polls over the last several years have consistently placed violence near the top of the public's list of concerns. This seems to happen regardless of whether homicide rates are climbing or falling. In this paper, we examine the time trends in homicide rates in the United States, and find that the fears are not totally inappropriate, even in the recent years when homicide rates have been falling. We find that, while there has been a significant decline in homicides committed by older offenders, homicides committed by younger offenders grew dramatically beginning in 1985 . An important factor in that growth has been a significant increase in the availability of guns to young people. By examining time trends in age-specific arrest rates for homicide (gun homicide compared to non-gun homicide) and similar trends in drug-related arrest rates (juveniles compared to adults), the role of gun availability, especially as it has risen through the recruitment of young people into drug markets, is identified as a probable cause of these homicide trends. Further examination of mortality rates-due to gun homicides compared to nongun homicides as well as gun suicides compared to non-gun suicides-for various age and race groups also implicates gun availability as a key contributing factor to the growth in youth homicide.

The November 1995 publication of the Federal Bureau of Investigation's ("FBI's") Uniform Crime Reports for $1994^{1}$ generated widespread enthusiasm that the growth in homicide rates experienced by the United States since the mid 1980s had finally come to an end. The report indicated that homicide rates peaked in 1991 with lower rates occurring over the next three years. To some observers, this may have indicated that the growing public anxiety about homicides might well subside.

In any event, concern over recent trends in aggregate homicide rates may have been misplaced. Those rates have been impressively steady for more than twenty years. ${ }^{2}$ Contrary to most people's perception that homicide rates have

Copyright $\odot 1996$ by Law and Contemporary Problems

* University Professor of Urban Systems and Operations Research, H. John Heinz School of Public Policy and Management, Carnegie Mellon University.

** Ph.D. student, H. John Heinz School of Public Policy and Management, Carnegie Mellon University.

1. FBI, U.S. DEP'T OF JUSTICE, 1994 UNIFORM CRIME REPORTS (1995).

2. See infra Figure 1. All figures appear in the Appendix, at pages 19-24. 
been increasing dramatically over time, the time series of homicide rates from 1972 through 1995 (Figure 1) shows no discernible trend. Instead, rates have oscillated between eight and ten per 100,000 since 1972. In contrast, the time series for robbery rates, which follows a very similar oscillatory pattern, does display a slight upward trend whose slope is approximately one percent of the mean of the series. ${ }^{3}$

II

Disaggregation of Homicide Rates by Age and WeApon

\section{A. Age Distribution}

The aggregate homicide rate shown in Figure 1 is based on reports of homicides to the police. Because homicides are reported as "counts," these data do not lend themselves to disaggregation by demographic group. However, because homicide rates differ considerably across different demographic groups, it is essential to disaggregate these data in order to discern whether changes in the aggregate rate are attributable to large changes by some specific demographic group and/or whether these changes are attributable to a change in the group's rate or in its number. Disaggregation is also essential to determine whether a net decline in the aggregate rate may conceal underlying dynamics such as a growth in one group and a decline in another. That explanation might be somewhat less comforting than an across-the-board decline, especially if the group that is growing provides an indication that its growth might soon overtake the one that is declining.

Disaggregated rates are typically developed using information on arrest rates, where the demographic characteristics of the arrestees are recorded. Disaggregation of homicide rates by age group highlights the fact that the decline in recent years is a net result of a decline in homicide arrests of older offenders, accompanied by a significant growth in homicide arrests of younger offenders. As Figure 2 shows, this development is reflected in the dramatic growth in the age-specific arrest rate for homicide between 1985 and 1994. While the age-specific homicide arrest rates between 1970 and 1985 were almost constant, there was a sharp growth in the homicide arrest rate of eighteen-yearolds and the surrounding ages from 1985 until 1992. ${ }^{4}$ Examination of the right side of the age-specific homicide arrest rate curve shows that the arrest rate for all ages beyond thirty is even lower in 1994 than it was in 1985.

The trend between 1985 and 1994 in the age-specific arrest rate for homicide is shown in Figure 3, which presents the ratio of the 1994 rate to the 1985 rate.

3. Id.

4. Figure 2 and others displaying age and race-specific arrest rates are drawn from Federal Bureau of Investigation, U.S. Dep't of Justice, Uniform Crime Reports, Age-specific Arrest Rates and Racespecific Arrest Rates for Selected Offenses 1965-1992 (1993). No updates to these age-specific rates for 1993 and 1994 are available from the FBI. 
It is evident that homicide arrest rates have more than doubled for all ages under eighteen, are about the same for adults in their mid-twenties, and are about twenty percent lower in 1994 than in 1985 for ages thirty and older. The decrease for those ages thirty and older is very likely attributable to the fact that prison populations in the United States almost doubled over that period. ${ }^{5}$ The incapacitative effect of imprisonment is much more pronounced at later ages, than at the younger ones.

\section{B. Measurement Errors in Age Distribution}

Assessment of these age-specific trends must recognize that arrest rates can differ from actual offending rates. The difference could be a consequence of differential vulnerability to arrest by different demographic groups. For example, young offenders may be more easily arrested because they are less skillful in avoiding arrest, or they may be less vulnerable to arrest because their victims are more often strangers, and finding the perpetrator in a strangerhomicide is much more difficult than in one involving intimates.

Another concern about using arrest rates is the possibility that multiple arrests may occur more often in some demographic groups than in others. This difference may be a consequence of more aggressive police practices in dealing with some groups, leading to multiple arrests for a single homicide. Or it may result if homicide by some groups, especially the younger ones, are more likely to be committed by multiple offenders than single offenders. A homicide committed by a gang, for example, could well result in multiple gang members being arrested for the same homicide; that would contribute to a higher arrest rate for the gang members' age group.

Although these measurement problems are certainly valid, the concern over them diminishes somewhat when one is examining time trends. The time trends would be distorted only if there is a time trend in the factors contributing to these distortions. Although that could well be the case-for example, if young people committing homicide today are more likely to be operating in gangs-the emphasis must then be on the shifts in those distorting factors. We are exploring these issues in some detail using data from the FBI's Supplemental Homicide Reports. These data identify the number of victims, the number of offenders (when that is known), and the demographic characteristics of each victim and offender for each homicide incident. This enables one to track over time the trends in the underlying behavior as well as the trends in the distorting factors. In view of the large differences observed among juvenile offenders, it is reasonable to anticipate that many of the trends observed might be changed

5. TRaCy L. SNELl, U.S. DeP'T OF JUSTICE, 1993 CORRECTIONAL POPULATIONS IN THE UNITED STATES 8, tbl. 1.6 (1995) (stating that the number of prisoners in state or federal correctional institutions with sentences of more than one year climbed from 480,568 in 1985 to 846,277 in 1992 , an increase of $76 \%$ ). 
somewhat by these corrections, but the basic thrust is not likely to be changed dramatically.

\section{Weapon Use}

Aside from the shift in the age distribution of those arrested for homicide, another striking feature of the growth in homicide rates by youth is the dramatic growth in the use of guns in those homicides. Figure 4 shows the number of gun and non-gun homicides committed by juveniles aged ten through seventeen since $1976 .{ }^{6}$ In the early part of that period, from 1976 through 1984 , gun and non-gun homicides were fairly constant in absolute numbers and in their fairly stable 60/40 ratio. That situation began to change in a major way in about 1985 , and the number of gun homicides more than doubled by 1991, with no accompanying growth in the number of non-gun homicides. This suggests that beginning in 1985, guns have had a strong impact on homicide statistics for youth.

\section{III}

\section{THE DRUG CONNECTION}

\section{A. Juveniles}

A third important transition that occurred in 1985 was in the arrest rate of juveniles for drug offenses. Because the time patterns are very different for whites and nonwhites (predominantly African-Americans), we examine these two groups separately. As Figure 5 shows, the arrest rate for drugs prior to 1965 was virtually negligible for both white and non-white racial groups; then, with the spread of marijuana use and associated intensified police enforcement, the drug arrest rate rose sharply and in parallel for the two groups. The arrest rate for white juveniles reached a peak in 1974 and then underwent a fairly steady decline thereafter. This reversal probably reflects less of a decline in drug use than a policy shift responding to the large numbers of middle-class juveniles who were being caught up in the criminal justice system. These concerns gave rise to a general response that led in some places to effective decriminalization of marijuana and, in others, to far less aggressive pursuit by police of marijuana possession offenses. ${ }^{7}$

The drug arrest rate for non-whites rose at approximately the same rate as that for whites in the 1960s, but then leveled off at a rate that was below that for whites throughout the 1970s. Rather than display a decline similar to that

6. Figure 4 is derived from chart data in James Fox, Teenage Males are Committing Murder at an Increasing Rate (Apr. 1993) (unpublished report, prepared for the National Center for Juvenile Justice). This report is based on data from the FBI's Supplementary Homicide Reports, a compilation of detailed reports on individual homicides provided by police departments.

7. For example, in some jurisdictions the penalty for possession of marijuana has been lowered to as little as five dollars. 
of whites, the non-white rate stayed rather steady throughout the 1970 s and early 1980s. In 1985, the non-white rate grew sharply, more than doubling the 1985 rate by 1989 .

\section{B. Adults}

Figure 5 presents a rather different picture for juveniles than Figure 6 does for adults. Figure 6 shows that the rise in drug arrests in the 1960s for white adults was less steep than that for non-whites. Similar to the drug arrest rate for white juveniles, the drug arrest rate for white adults also peaked in 1974 . However, after 1974, the rate for white adults maintained a fairly stable level, For non-white adults, the rate rose quickly until the 1970 s, where it stayed at a fairly constant level. Then around 1980, the drug arrest rate for non-white adults began a rather steep rise that accelerated after 1985.

\section{IV}

\section{A Hypothesized Process Linking Youth Homicide, Guns, And ILLICIT DRUG MARKETS}

The information in Figures 2 through 6 suggests a link between the growth after 1985 of illicit drug markets, recruitment of juveniles for those markets, the diffusion of guns among juveniles, and the doubling of juvenile homicide rates.

\section{A. The Growth In Drug Markets}

There is a widespread view that drugs, and crack cocaine in particular, are somehow involved in the growth of the youth homicide rate. While there may well be some pharmacological influences of crack that increase violent behavior, there is no obvious connection between the use of crack and the accumulation of guns, especially in the hands of young people. One must turn to the drug markets, rather than the drugs themselves, for an assessment of those changes.

Crack arrived first in the largest cities like Los Angeles, New York, and Miami in about 1983, and then came to other cities at various times during the following decade. When crack arrived, it was a significant new product in the marketplace. Unitl then, cocaine was principally sold in powder form, and the quantities involved in a transaction at the retail level required an outlay of at least several hundred dollars and perhaps as much as several thousand dollars. This cost limited consumption primarily to middle-class individuals who could afford to spend that much money in a single transaction.

However, crack cocaine had sufficient bulk that it could be sold one "hit" at a time for a price on the order of five to ten dollars. This low price significantly expanded the consumer market for cocaine to people who had far less money than those who had typically been purchasing the powder form of the drug. Thus, the introduction of crack both expanded the number of buyers and significantly expanded the number of transactions per week for each buyer. These new, less wealthy consumers had to purchase the drug much more 
frequently because they could not afford to buy in the quantities that powdercocaine purchasers managed. This double effect-many more consumers purchasing at a higher rate-resulted in a sharp increase in the need for sellers to accommodate that demand.

\section{B. Recruitment Of Juveniles}

The drug supply system, ever ready to satisfy demand, responded through major recruiting efforts for new sellers, focusing predominantly on juveniles. ${ }^{8}$ Juveniles were attractive candidates for several reasons. First, they had less risk of punishment because mandatory minimum sentences, which were increasingly being applied to adults, typically did not apply to juveniles. Thus their risks were lower, and the risk premium that had to be paid to them could be lower. Furthermore, young people typically display less concern than adults over even the same levels of risk. Second, the recruitment could exploit the sense of economic hopelessness that is widespread among many young Americans, particularly African-Americans, in urban areas'; drug selling represented a powerful attraction to those who saw no opportunities for themselves in the legitimate economy. Thus, the massive recruiting efforts for new drug sellers were facilitated by the strong mutual attraction between drug dealers and the young people, particularly those youths living in urban ghettos. The result of those efforts-a significant increase in non-white juvenile drug arrests after 1985-is reflected in Figure 5.

\section{Guns For Protecting The Drug Sellers}

Individuals operating in illicit drug markets are very vulnerable to theft because the wares they carry and the revenues they get from selling them are illegal. Because they cannot rely on access to the police in ways that protect legitimate economic activity, they are forced to resort to their own means of protection. That self-protection typically involves becoming armed with a handgun, a standard tool of the trade in the drug industry. Gun availability has long been recognized as an important contributor to violence. ${ }^{10}$ In this case, however, gun availability is accelerated because of its connection with the illegitimate drug markets. For example, the drug dealer who recruits youths could well take into account as a criterion for selection a recruit's willingness and ability to use the gun to defend himself. This could result in a reasonably widespread presence of guns among the juveniles who become involved in the drug trade. The appearance of weapons as an adjunct to the crack trade has

8. See infra Figure 5.

9. See generally William J. Wilson, WHEN WORK Disappears: THE WORLD OF THE NEW URBAN POOR (1996).

10. Philip J. Cook, special editor of this symposium, has studied this area intensely. See, e.g., Philip J. Cook, The Role of Firearms in Violent Crime: An Interpretive Review of the Literature, in CRIMINAL VIOLENCE 236 (Marvin Wolfgang \& Neil Weiner eds., 1982). 
been highlighted by the National Research Council ("NRC") Panel on the Understanding and Control of Violent Behavior. ${ }^{11}$

\section{Diffusion Of Guns}

However rapid the growth in recruitment of juveniles into the drug industry, that growth is far less than sufficient to account for the increase in juvenile homicides. To account more fully for the increase, one needs to invoke a broader process of diffusion of guns to a larger number of young people than those involved directly in the drug markets. This diffusion process was nucleated by the juveniles in the drug market, but their possession of guns is soon followed by others in connected networks-those who go to the same schools or travel in the same streets-finding a reason to obtain their own guns. Initially, these juveniles are motivated by self-protection. ${ }^{12}$ However, youths may subsequently acquire guns as a status symbol. ${ }^{13}$

As the availability of guns becomes more widespread, there is an increased incentive for additional youngsters in increasingly larger social networks to arm themselves. Thus an escalating process develops, where the possession of guns becomes widespread and continues to extend into juvenile networks well beyond those involved in the drug industry. This process is facilitated by the appearance of gangs, which tighten the social networks and serve as conduits for the diffusion of guns. The gangs armed with guns stimulate other gangs to acquire their own guns to defend themselves, and the diffusion continues.

Translating the presence of guns into homicides is undoubtedly facilitated by the seeming recklessness with which juveniles seem ready to use guns. Male teenagers have never been known to be experts at peaceful dispute resolution, and fighting has always been common among them. ${ }^{14}$

The contrast between adults and juveniles is reflected in Figures 7 and 8 , which depict the homicide arrest rates of whites and non-whites for the two age groups. For adults, both whites and non-whites show no significant rise in the homicide rate through the 1980s, with particularly stable rates after 1985 . Figure 7 is especially enlightening when compared to Figure 6, which indicates a sizeable growth in non-white adult arrest rates for drugs during the 1980 s. Although it is reasonable to presume that many of these adult drug offenders carried guns, it appears that adults, even those involved in the drug markets, used their guns with relative restraint. Other factors contributing to the

11. Understanding and PReventing Violence (Albert J. Reiss, Jr. \& Jeffrey A. Roth eds., 1993).

12. Joseph F. Sheley \& James D. WRight, NATIONAl InSTITUTE OF JUSTICE, GuN ACQUISITION AND POSSESSION IN SELECTED JUVENILE SAMPLES (1993) (study concluding that in a survey of students in center-city schools, $22 \%$ were found to possess guns and $68 \%$ cited protection as the main reason for their most recent gun acquisition).

13. Id.

14. This phenomenon has been depicted quite widely in various longitudinal studies of youth. See, e.g., Delbert S. Elliott et Al., MUltiple Problem Youth: Delinquency, SubStanCe Abuse, and Mental Health PROBlems (1989). 
differences in the adult and juvenile rates may be that social networks among adults are not as tight as they are among juveniles and that the need for adults to respond to the possession of weapons by others does not seem to be as strong.

When one looks at the juvenile arrest rate for homicide, one sees a very different picture. As Figure 8 shows, between 1985 and 1992, the arrest rate of non-whites increased by about 120 percent. This result is certainly consistent with the expectation generated by Figures 2 through 5 . However, it is somewhat surprising to note the sharp rise in the homicide arrest rate for white juveniles. Figure 5 provides no indication of their significant involvement in the drug industry. Thus, involvement in the drug industry, which seemed to be the most salient factor for explaining the growth in the non-white juvenile homicide rate, does not appear to be a strong contributing factor in the growth of the white rate.

This rise in the white juvenile homicide rate might be explained by the diffusion of guns, which can involve white as well as non-white youths. Although the diffusion process appears to have started predominantly with nonwhites (as evidenced by the growth in the non-white drug arrest rates), it could easily extend to whites. They go to many of the same schools and would inevitably feel the same need as the other non-drug dealers to protect themselves against their classmates who are carrying guns. ${ }^{15}$

Consistent with this possibility, Figure 8 shows that the growth in the white juvenile homicide rate did not begin until about 1988, three years after the upturn in the non-white rate. This observation is consistent with a diffusion hypothesis, because it would take some time for the presence of guns, initially in the hands of the non-white drug sellers, to prompt the sellers' closest companions-probably non-white, non-drug sellers-and, then, adjoining white communities to arm themselves.

\section{$\mathrm{V}$}

\section{Gun AVAILABILITy OR PROPENSITY FOR ViolenCE?}

The previous analysis ${ }^{16}$ suggests that the diffusion of guns played an important part in the growth of youth homicide rates. It still leaves unanswered, however, the question of the degree to which the growth can be attributed to the increased presence of guns as opposed to a greater propensity to engage in violence by the young people. If there is no change in youths' propensity for violence, then the presence of guns could account for a rise in the lethality of fights that would have otherwise occurred. In contrast, if there is no change in gun availability, a greater propensity to violence might result in youths employing guns-the most violent weaponry-more often. Obviously,

15. SHELEY \& WRIGHT, supra note 12.

16. The analysis was drawn from Alfred Blumstein, Youth Violence, Guns, and the Illicit-Drug Industry, 86 J. CRIM. L. \& CRIMINOLOGY 10 (1995). 
it is not necessary that either of these pure cases (greater gun prevalence with no increase in propensity to violence versus no shift in gun availability with a greater tendency to violence) need prevail; each influence could stimulate the other in a variety of ways (for example, greater gun availability could stimulate a taste for violence). Nevertheless, it would be valuable to determine which of the two is the more predominant influence.

If the predominant influence were gun availability, then one would expect to see a growth in gun homicides with no comparable growth in non-gun homicides. On the other hand, an increase in youths' propensity for violence might be reflected in a growth in both gun and non-gun homicides, perhaps with a greater growth in gun homicides because of the greater efficiency of guns in expressing violence.

One method for determining whether gun availability or propensity for violence is the more important cause of the growth in youth homicide rates is to focus on victimization rates rather than arrest rates. Because victims of homicide often resemble their killers in demographic characteristics, ${ }^{17}$ it is useful to examine the trends in homicide victimization rates by demographic group, particularly to see if the upward trends in homicide arrests of young people that began in 1985 are similarly reflected in the demographic-specific homicide victimization rates. In particular, if one can distinguish gun and nongun victimization rates, and if the gun rates increase sharply while the non-gun rates continue to be unaffected (as occurred in Figure 4), then the argument for the influence of gun availability compared to a propensity for violence would be stronger.

A second method for determining whether gun availability is the dominant influence is to examine the rate of other fatalities, such as suicides, which are less directly attributable to a propensity for violence. ${ }^{18}$ If one discovered an increase in gun suicides, with no comparable increase in non-gun suicides, then that should further strengthen the argument that gun availability is the principal influence in the dramatic increase in gun homicides. Because many suicides, particularly those by young people, are actually a "cry for help," even if not recognized as such by the perpetrator, then the presence of a gun as the suicide instrument is far more likely than other forms of suicide to transform that cry for help into a fatality. That influence could be expected to be strongest among groups that had the least prior exposure to guns and were not familiar with them.

17. FBI, Supplementary Homicide Reports (unpublished magnetic tape, updated regularly; available upon request from FBI) (noting that analyses of victim and offender characteristics highlight the similarity of victim and offender with the exception of intra-family homicides).

18. Some psychological theories of suicide do suggest that it is a propensity for violence turned inward, but it does seem reasonable to believe that many more complex motives enter into a person's motivation to commit suicide than in the case of homicide. 


\section{A. Data From the Mortality Detail Files}

The Mortality Detail Files, which are maintained by the National Center for Health Statistics and based on coroner reports and death certificates filed at the county level, provide an additional basis for exploring the relative influences on the increase of gun homicides. ${ }^{19}$ From these data, one can extract individuallevel data on deaths by homicide, suicides, and accidents with guns or other means.

We obtained the 1968 through 1991 data from the Mortality Detail Files and then calculated the time series for the homicide and suicide rates for eight demographic groups: whites and African-Americans in the four age ranges fifteen to nineteen, twenty to twenty-four, twenty-five to twenty-nine, and thirty to thirty-nine. Annual census estimates for the population in each group were used to provide the denominator for each rate calculation. These time series were then analyzed to determine the degree to which they displayed a comparable transition around 1985.

\section{B. Analysis by Spline Regression ${ }^{20}$}

A method of spline regression was used to identify the turning points in the various time series. We provided an opportunity for at most two turning points in each of the time series, with linear regression used to fit a line between the turning points, coupled with a requirement that these individual line segments form a continuous fit. The turning points were restricted to occur at integer (year) values. By performing a grid search over all of the turning point combinations, the optimum turning points are chosen to be those that minimize the residual sum of squared deviations around the fitted regression lines. The appropriate number of turning points required for any time series was decided based on a modified Chow F-test.

The initial attempt was to see to what extent the data would fit adequately with a single line with no turns. This line was then compared with a two-piece line and a single turning point. If the two-piece line was indicated as preferable, then it was compared to a three-piece line. In each of these comparisons, using an additional line (and an associated additional turning point) had to make a significant difference in the quality of the fit to the data. In some cases, even though a three-piece line might have been better than a two-piece line, it was compared with a one-piece line to see if that was still significantly better.

19. U.S. Dept. of Health \& Human Services, National Center for Health Statistics, Mortality Detail Files 1968-1991 (unpublished computer files).

20. For an explanation of spline regression, see Derek J. Hudson, Fitting Segmented Curves Whose Join Points Have to Be Estimated. J. AM. STAT. ASSOC. 1097 (1966). 


\section{Results}

The results of these analyses are depicted in Figure 9 for homicide and Figure 10 for suicide. We present the data and the fitted lines for AfricanAmericans $^{21}$ (on the left) and whites (on the right) and for each of the four age groups arrayed vertically. The same scale is used for all ages within a race group, but the scales between the race groups can be different. Each graph depicts the gun-related rates (typically with three lines) as well as the non-gun rates (typically best fit with a single flat line).

1. Homicide. The trends for gun homicides are strikingly similar to those we have seen in the arrest statistics described above. For African-Americans, there is the consistent pattern of a peak in 1972 (except for the fifteen to nineteen age group, although it even had a slight peak at that time), a subsequent decline, and then a trough in 1985 (again, except for the fifteen to nineteen age group, whose trough occurred in 1987). The growth rate after the trough varies inversely with age, with the largest growth rate (a slope of 9.9) displayed for the fifteen to nineteen age group, somewhat less (8.4) for the twenty to twenty-four group, still less (3.8) for the twenty-five to twenty-nine group, and only slight growth (1.4) in the thirties.

The situation for gun homicide victimizations for whites is similar. Their initial peak occurred somewhat later than the peak for African-Americans: in 1980 for the two youngest groups; in 1981 for ages twenty-five to twenty-nine; and in 1974 for the oldest group. All groups showed a statistically significant decline after the peak and then a trough in the late 1980s: in 1987 for the fifteen to nineteen age group; in 1988 for the twenty to twenty-four and thirty to thirtynine age groups; and in 1984 for the twenty-five to twenty-nine age group. The growth past the trough was greatest for the two youngest groups and still significant but less sharp for the two older groups. Here again, as with the juvenile homicide arrest data of Figure 8 , there is a three-year lag between the African-American and white turning points for the twenty to twenty-four and the thirty to thirty-nine age groups. We also see somewhat more diffusion in the homicide victimization age structure than is the case in the arrest data. In homicide arrests, the growth was more sharply focused in the fifteen to nineteen age range, with some small growth for the early twenties age group, and no growth for the above twenty-five age group.

In contrast, Figure 9 shows that a larger variety of age groups reflect higher homicide victimization rates after 1985 . The source of this greater diffusion of victimization rates may be that while young people typically kill other young people, they can also kill some older people, either as explicit targets or as innocent bystanders.

21. The Mortality Detail Files draw a distinction between blacks and whites. However, in the text of this article, the terminology "African-Americans" will be employed. 
In contrast to the gun homicides, there are no turning points in any of the non-gun homicide rates for any of the African-American groups. All have virtually continuous slopes, slightly downward. For the whites, the slopes are less continuous, mostly with slight changes in the early 1980s, but far less pronounced than in the case of the gun homicides.

2. Suicide. The suicide data in Figure 10 reveal a similar pattern among the African-Americans, with less clear an effect among the whites. For the African-Americans, the earlier peak in gun suicides occurs in 1972 (except for the twenty-five to twenty-nine age group, where it occurs in 1975), and the trough is in 1983 or 1984 for all age groups. The subsequent rise is statistically significant in all groups except for the oldest group. The growth rate in gun suicides varies inversely with age, with the sharpest rate for the two youngest groups.

For whites, where suicide has traditionally been more common than among African-Americans, the gun suicide pattern shows a peak at about the same time that their gun homicide rate peaked (the late 1970s) and then shows a subsequent slight decline. The only deviation from that pattern is in the fifteen to nineteen age group, which begins to increase in 1974 following a flattening of the earlier growth in 1979. Thus, the growing availability of guns in the mid1980 s seems to influence the suicide rates for only the youngest of the white age groups.

For African-Americans, the non-gun suicide rate has been more dynamic than their non-gun homicide pattern. However, there is no indication in any of the age groups of the recent growth in the gun suicides. For most of the groups, both African-American and white, the recent gun-related suicide rates have been flat or declining.

\section{VI \\ CONCLUSION: \\ POLICY IMPLICATIONS}

\section{A. Reduce The Availability Of Guns To Young People}

The first and most evident implication of the results presented here strongly suggest the importance of gun availability, particularly to the young people in the fifteen to nineteen age range. This emphasizes the necessity of developing approaches to reduce the availability of guns to these youth. These are issues predominantly for local police, because it is they who engage the youth directly in the streets of their communities. Many approaches have been tried with considerable success. For example, New York City has pursued aggressive stop- 
and-frisk procedures wherever they could justify such actions. ${ }^{22}$ Charleston has offered a $\$ 100$ bounty for reports of illegal guns that can be confiscated. ${ }^{23}$ Such an approach facilitates the confiscation of guns, but, perhaps more important, it also inhibits those carrying guns from brandishing them and thereby diminishes the incentives for others to obtain their own guns. St. Louis police ask for permission to search homes in high-violence communities and confiscate any firearms they find in the searches. ${ }^{24}$ In exchange, the police promise not to press charges for any weapons offenses. The authorities report more than ninety percent compliance in these searches. All of these approaches appear reasonable, and the selection of any particular approach for any particular community will depend strongly on the tastes and interests in that community.

\section{B. Attack The Gun Markets Selling To Youth}

A second approach involves attacking the market that provides youth with access to guns. It is illegal almost everywhere, and is specifically a federal crime under the 1994 Crime Act, ${ }^{25}$ to sell a gun to a juvenile. Because so much of this traffic is carried out in interstate commerce, there is an important federal role in disrupting these markets. Compared to the drug markets, whose products are difficult to trace, guns have serial numbers that allow them to be traced at least to the initial source, a federally licensed firearm dealer, and then perhaps from there to the secondary sources that gave rise to their distribution. This, coupled with intelligence information garnered from the youth who carried the gun, should make pursuit of the illicit gun traffic far more effective than has been the case with drug trafficking.

\section{Shrink Drug Markets}

A third approach focuses on efforts to shrink the drug markets to eliminate one of the principal causes for gun demand by youths. These drug markets initiated the propagation of guns by recruiting young people as drug sellers. Shrinking the markets entails a mixture of efforts directed at prevention and treatment, but could also be approached through various efforts to medicalize treatment of the serious addicts who comprise a disproportionate fraction of the demand in drug markets. These issues will be of particular concern as new drugs begin to arrive and new markets develop to sell them.

22. Lori Montgomery, Crime Falls in Big Cities as Murders Drop by $8 \%$, PITTSBURGH POSTGAZETTE, May 6, 1996, at A1; John J. Dilulio, Jr., How to Deal With the Youth Crime Wave, THE WEEKLY STANDARD, Sept. 16, 1996, at 30.

23. Information derived from author's personal communications with Police Chief Reuben Greenberg of Charleston, South Carolina (March 1995).

24. Information derived from author's personal communication with Richard Rosenfeld of the University of Missouri-St. Louis who is evaluating the program in place at the St. Louis police department. (1994).

25. Violent Crime Control and Law Enforcement Act of 1994, Pub. L. No. 103-322, 108 Stat. 1796 


\section{Develop Improved Socialization}

While the previous suggestions are focused primarily on achieving short-term effects and should be initiated early, it is important to recognize that the existence of large numbers of disaffected youth who see no opportunities in the legitimate economy or who feel disconnected from legitimate society will often represent profound potential for disruption. The United States has always viewed socialization as primarily a responsibility of the family. In earlier times, there were many backup resources available when the family was not able to carry out its responsibility. These included proximate extended families, churches, and other members of the community who provided assistance to the family or themselves took on the socialization responsibility.

In the current era when dysfunctional families are more numerous, largely because of the startling growth in out-of-wedlock births (about thirty percent in the United States) ${ }^{26}$ and high divorce rates (about fifty percent of U.S. marriages end in divorce), ${ }^{27}$ the need for such backup resources is perhaps greater than ever. Unfortunately, those backup resources seem to have atrophied: Individual mobility has created greater distance from extended families; churches, with some striking exceptions, seem to have lost touch with their communities, or at least with those individuals who most need their support; and communities themselves are far more atomized.

Thus, a continuing problem for the United States is finding a way to support the increasing numbers of dysfunctional families in socializing their young people. The need to address this question will become increasingly important over the next fifteen years as the number of youths in peak crime ages (around eighteen) increases by about twenty percent. ${ }^{28}$

The suggestions posed here cover a broad array of policy options ranging from immediate police tactics to fundamental rethinking of our socialization needs. They can serve as a reference point as legislatures create legislation designed to combat this pressing problem relating to individual safety and wellbeing.

26. Frank F. Furstenberg, The Future of Marriage, in AMERICAN DEMOGRAPHICs 34 (June 1996); Barbara Vobejda, Americans Delay Trip to the Altar; Single Parent Home is as Often Result of No Marriage as Broken One, WASH. POST, Mar. 13, 1996, at A3.

27. Susanne M. Biancki \& Daphne Spain, Women, Work, and Family in America, in POPulation Bull. 12 (Dec. 1996) (citing ANDREW CHERLIN, MARRIAGE, DIVORCE, REMARRIAGE 24-25 (1992)). 28. Blumstein, supra note 16, at 35 fig. 13 (figure based on data from U.S. Bureau of Census). 


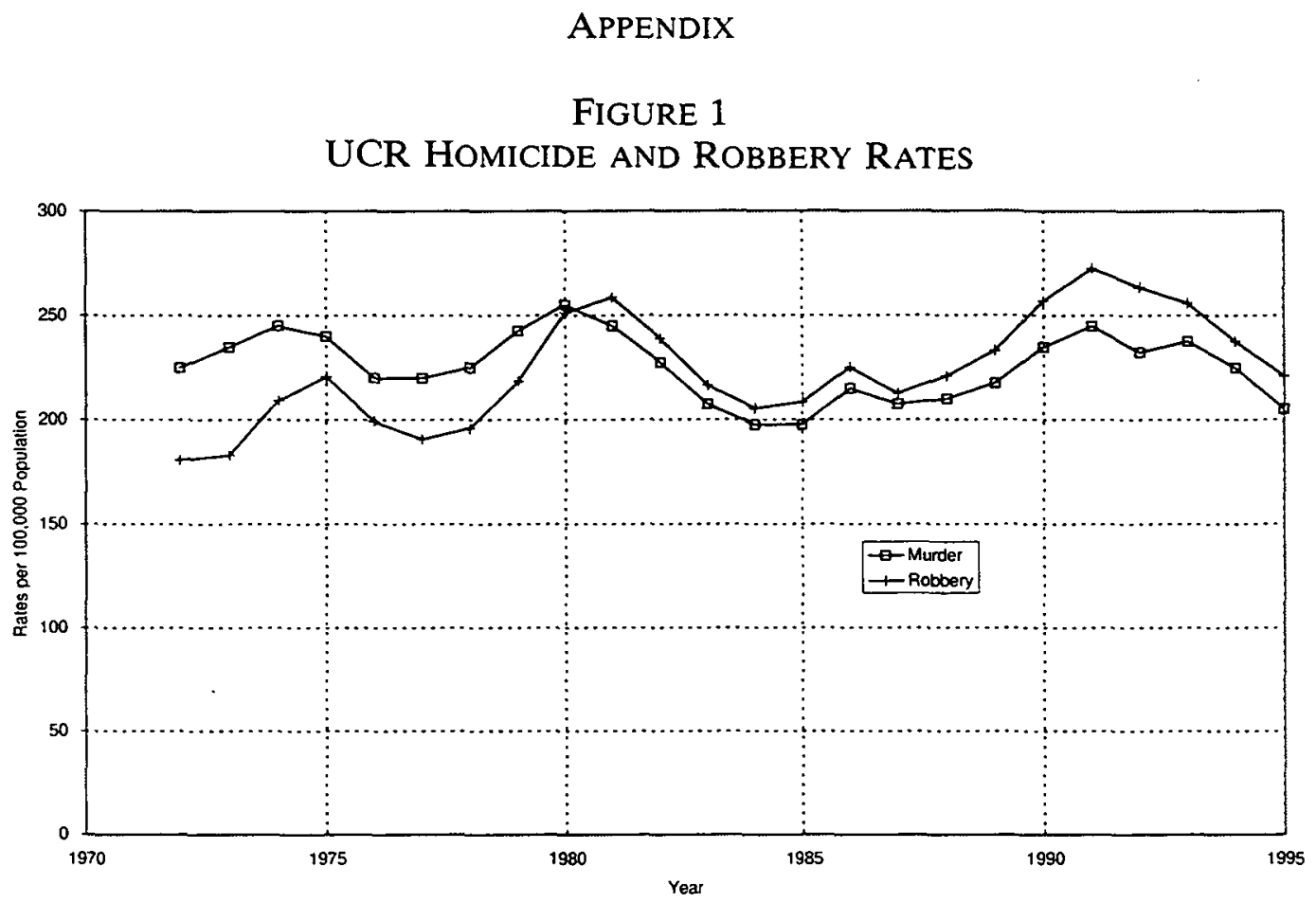

FIGURE 2

AGE-SPECIFIC Homicide RATE, 1985-1992

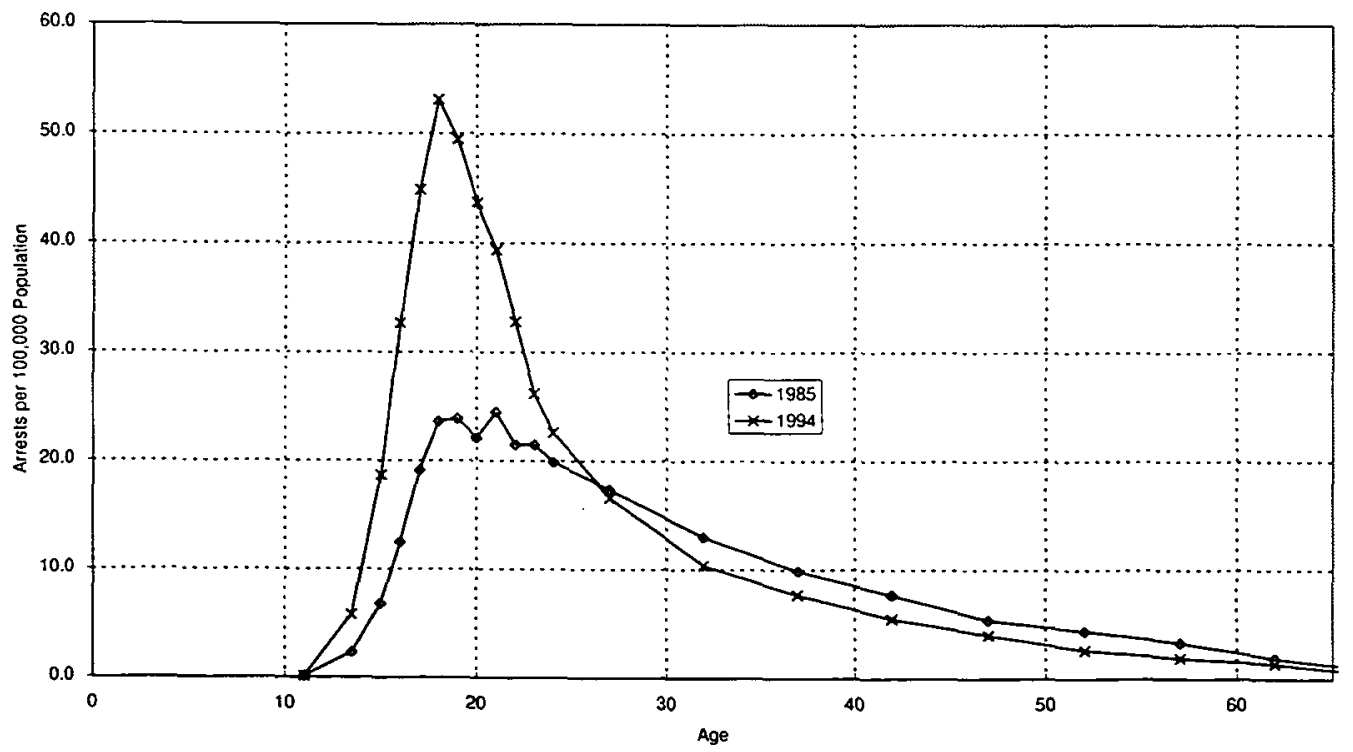


FIGURE 3

Ratio of 1992 to 1985 Age-SPECIFIC Homicide ARRESt Rates

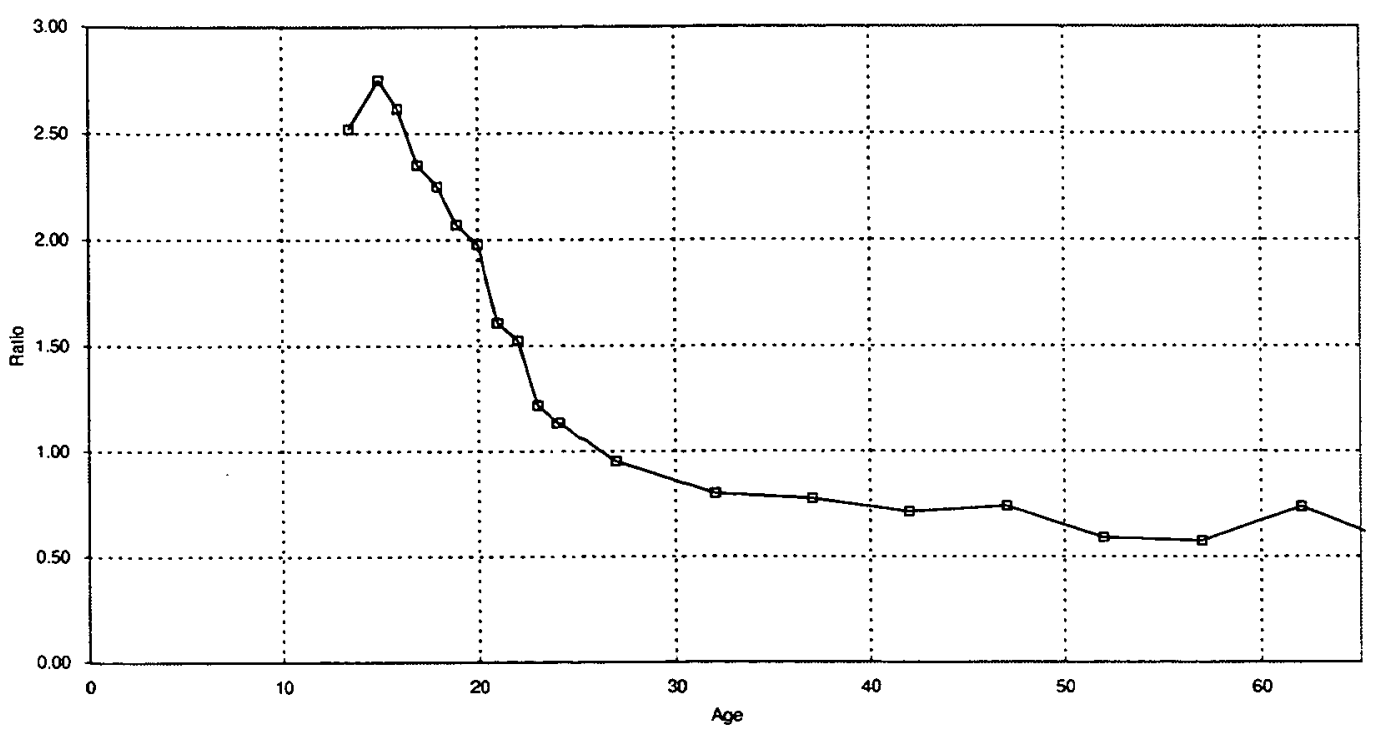

FIGURE 4

NUMBER OF GUN AND NON-GUN HOMICIDES

WITH JUVENILE OFFENDERS (AGES 10-17)

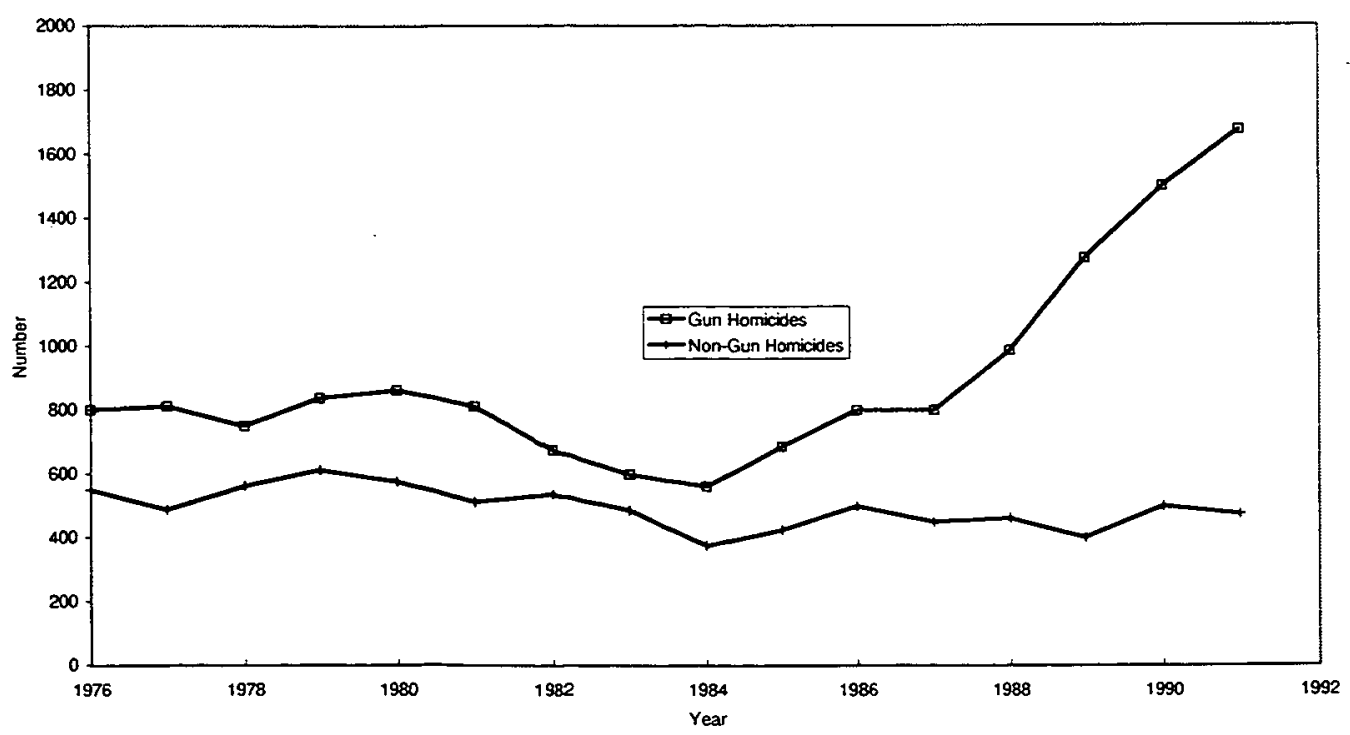


FIGURE 5

DRUg ARREST RATE FOR JUVENILES

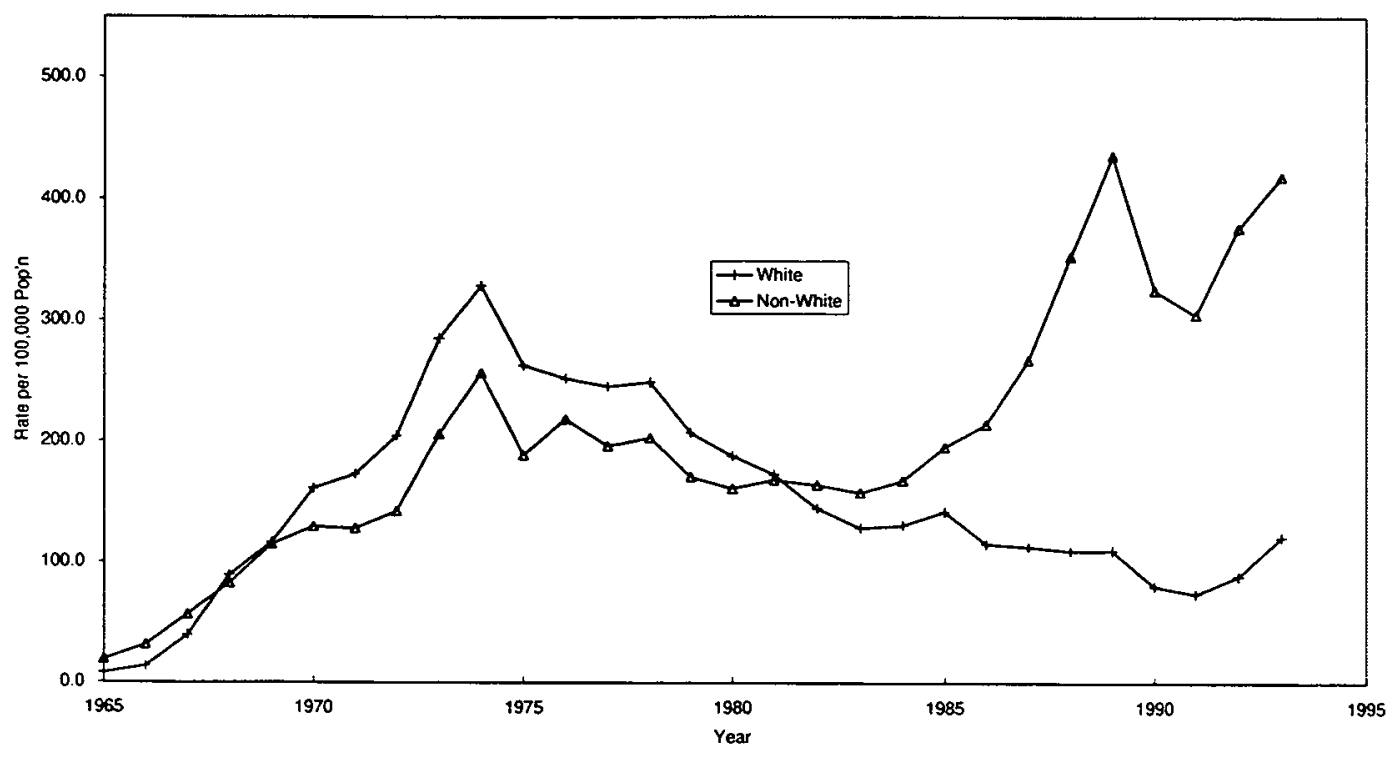

FIGURE 6

DRUG ARREST RATE FOR ADULTS

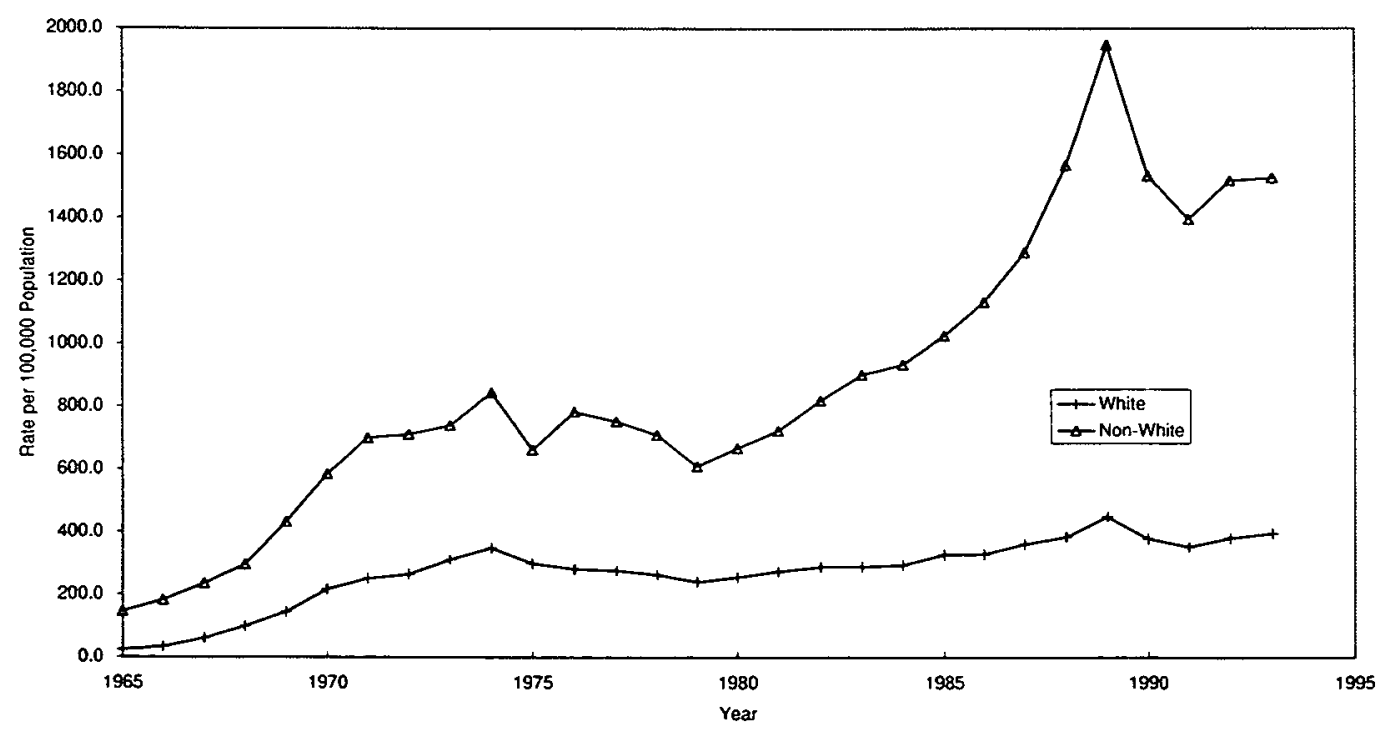


FIGURE 7

HOMICIDE ARREST RATE FOR ADULTS

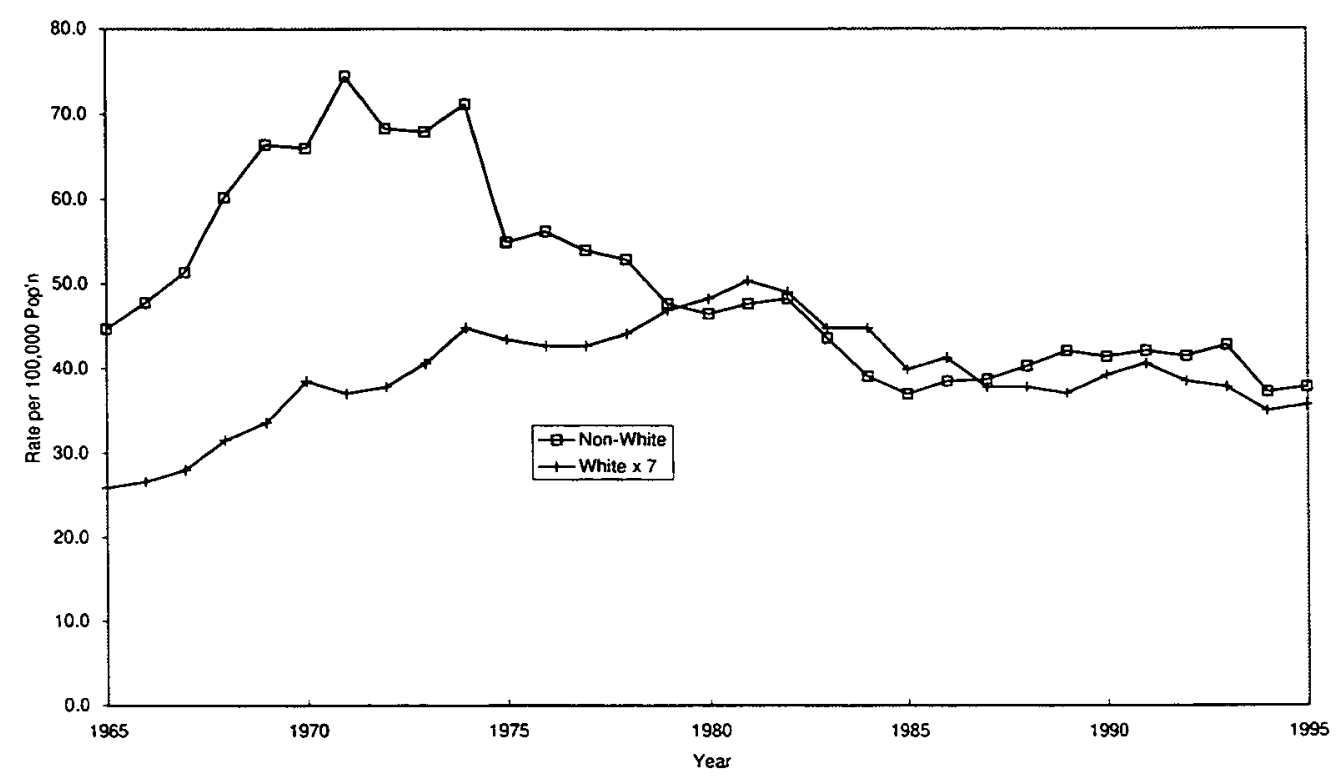

FIGURE 8

Homicide ARREST RATE FOR JUVENILES

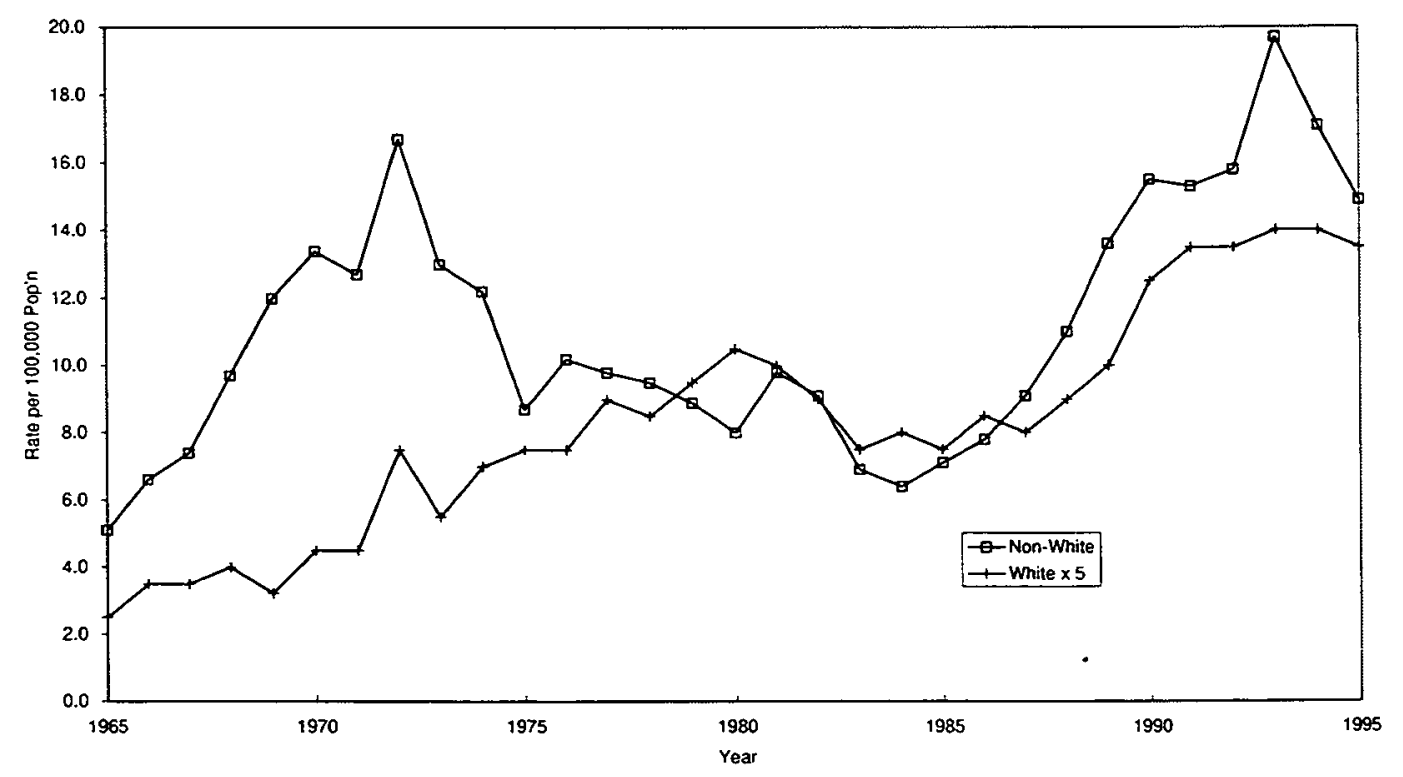




\section{FIGURE 9}

HOMICIDE VICTIMIZATION RATES

Homicide (Vict.) Rates, Blacks 15-19

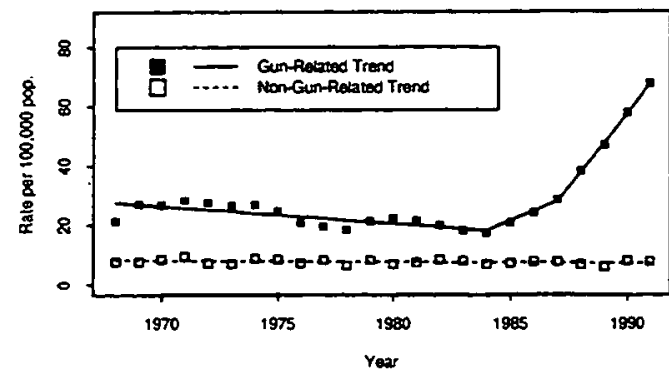

Homicide (Vict.) Rates, Blacks 20-24

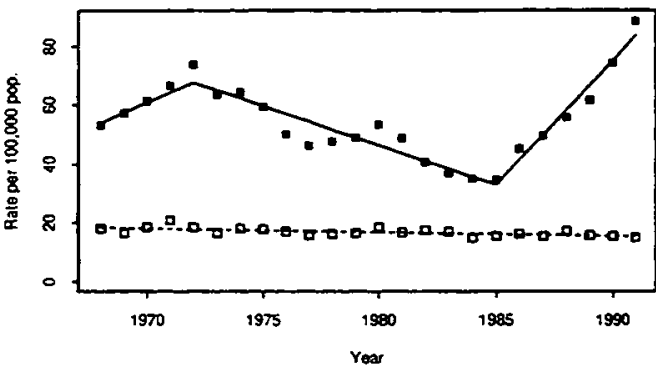

Homicide (Vict) Rates, Blacks 25-29

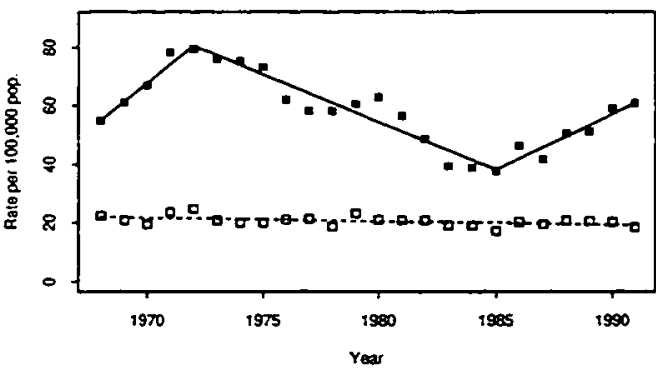

Homicide (Vict.) Rates, Blacks 30-39

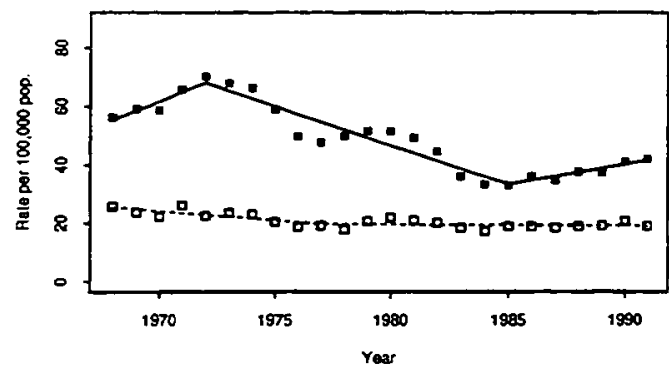

Homicide (Vict.) Rates, Whites 15-19

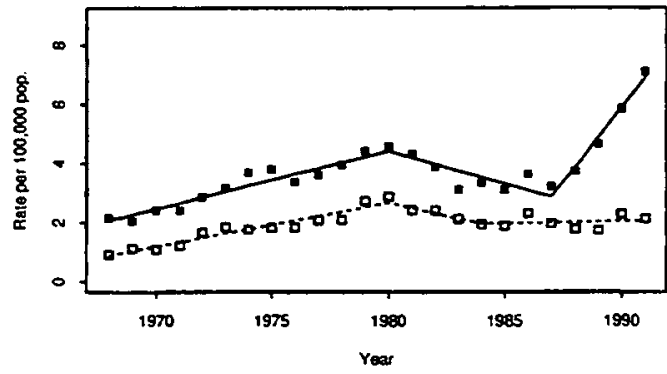

Homicide (Vict.) Rates, Whites 20-24

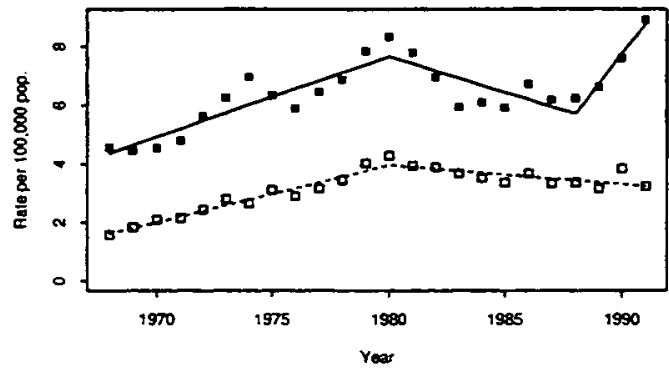

Homicide (Vict.) Rates, Whites 25-29

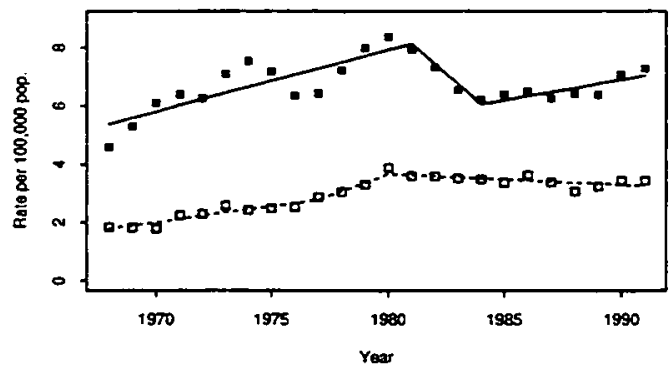

Homicide Nict.) Rates, Whites 30-39

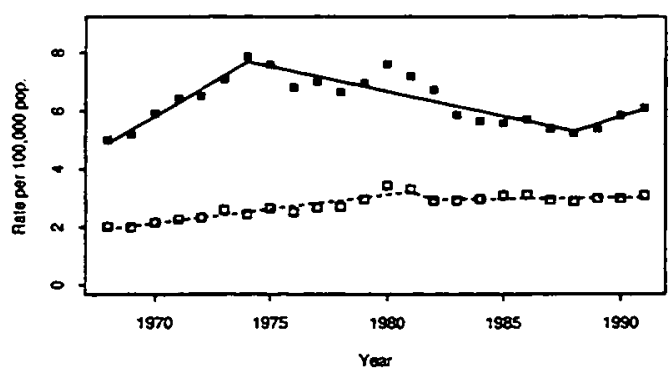


FIGURE 10

SUICIDE RATES

Suicide Rates, Blacks 15-19

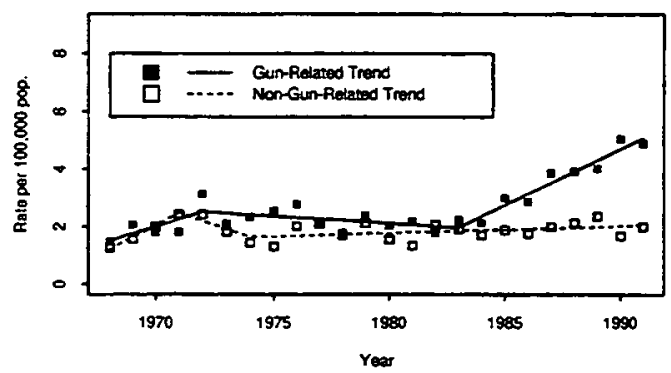

Suicide Rates, Blacks 20-24

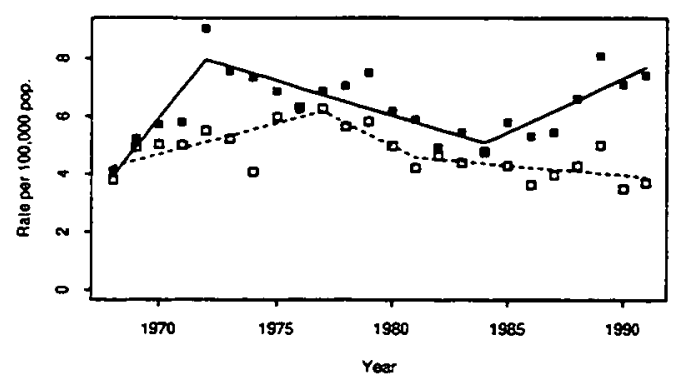

Suicide Rates, Blacks 25-29

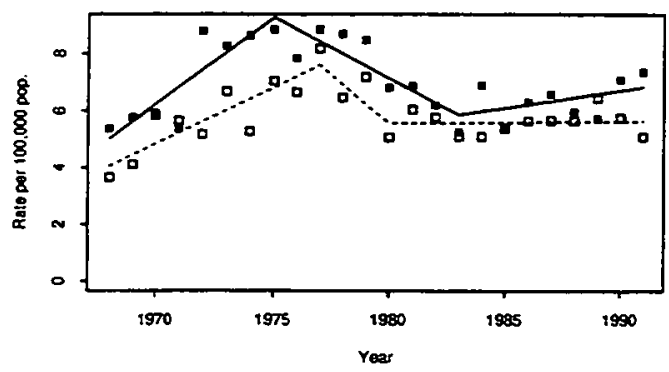

Suicide Rates, Blacks 30-39

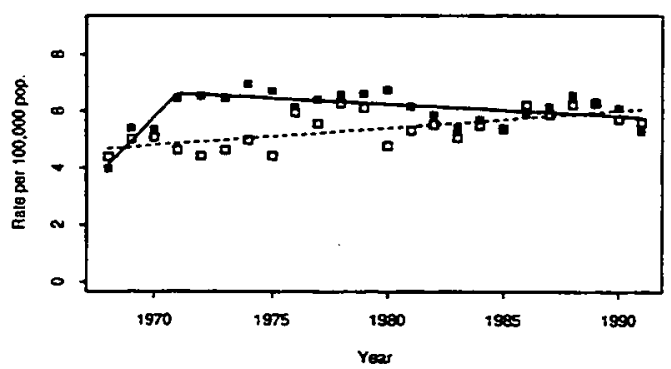

Suicide Rates, Whites 15-19

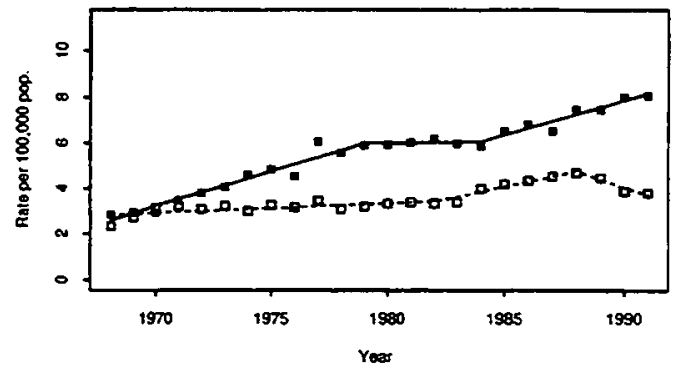

Suicide Rates, Whites 20-24

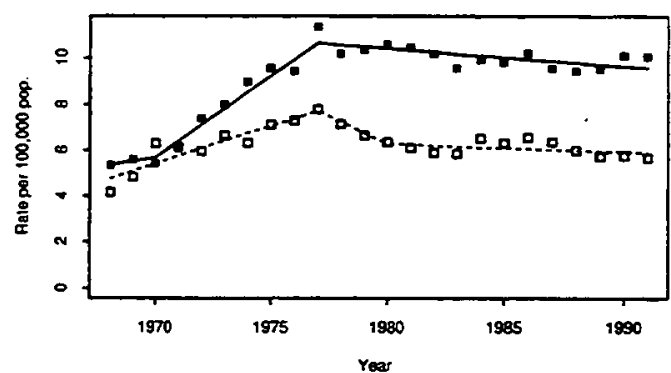

Suicide Rates, Whites 25-29

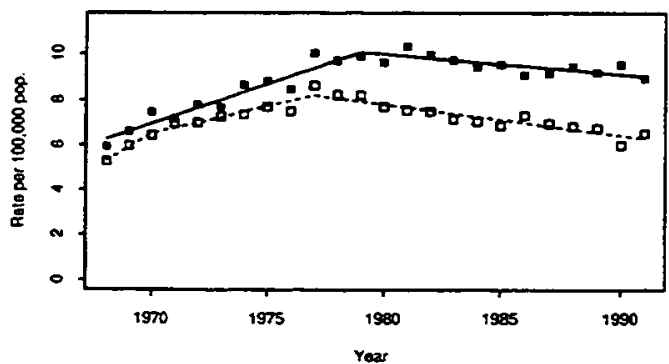

Suicide Rates, Whites 30-39

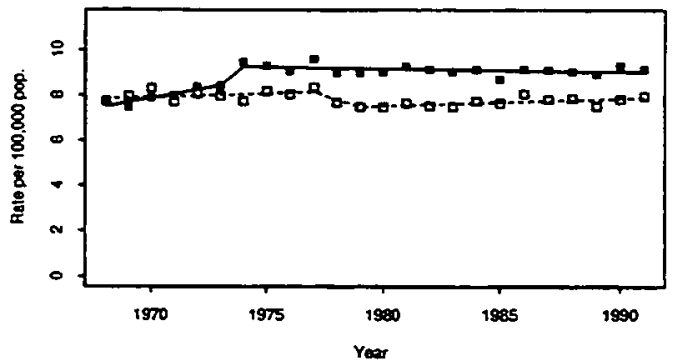

